\title{
HOMENAJE A PASCUAL RIVAS CARRERA
}

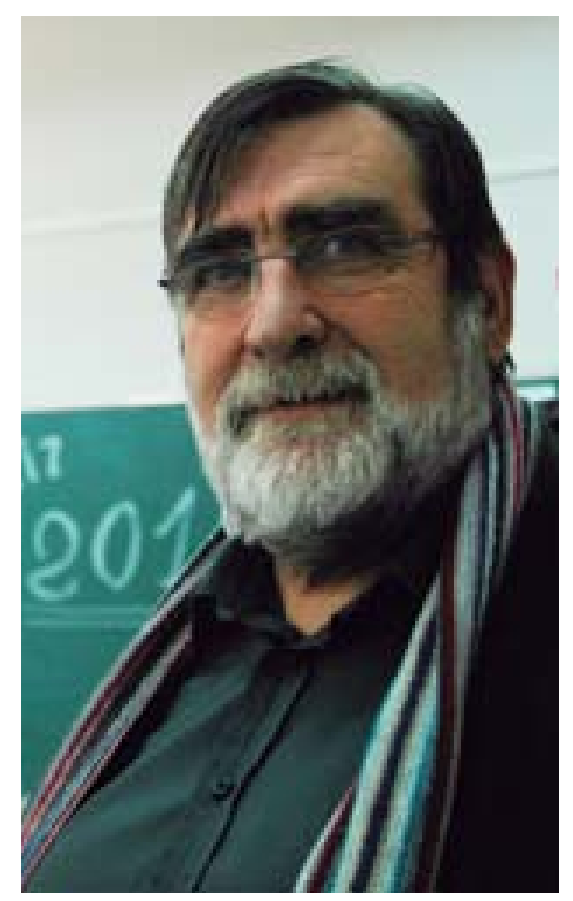

Este volumen de la SJP está dedicado a nuestro compañero, amigo y maestro Pascual Rivas Carrera, con motivo de su jubilación en septiembre de 2015. Pascual Rivas nació en Santander en 1945 y llegó a Granada en los años 60 para estudiar Ciencias Geológicas. Terminada la licenciatura, continuó en la Universidad de Granada haciendo su Tesis Doctoral bajo la dirección de la Dra. Asunción Linares, catedrática de paleontología. Su tesis se centraba en el estudio de los ammonites del Jurásico Inferior de la Zona Subbética, uno de los dominios de las Cordilleras Béticas, que entonces eran el objetivo fundamental de la investigación de todos los departamentos relacionados con la geología en Granada. Los ammonites, por otro lado, eran uno de los grupos de fósiles, junto con los foraminíferos, a los que se dedicaban casi todos los esfuerzos de investigación paleontológica, fundamentalmente dirigida a la bioestratigrafía, con el ánimo de datar los materiales sedimentarios que componen los distintos dominios béticos. En este contexto, Pascual fue coautor de trabajos que plantearon modelos de evolución sedimentaria de las Zonas Externas de la Cordillera Bética que en gran medida siguen vigentes en la actualidad. Ya como profesor, y siguiendo en esa línea de investigación, obtuvo una plaza de adjunto y, posteriormente, una de agregado en el Departamento de Paleontología de la Universidad de Granada. Es catedrático de esta universidad desde 1983. A través de la dirección de tesis doctorales y la colaboración con paleontólogos de la propia Universidad de Granada y de otras universidades, especialmente de la Universidad Complutense de Madrid, amplió sus líneas de investigación a otros intervalos geológicos, a otras cuencas mesozoicas y a otros grupos de fósiles. Al mismo tiempo, abrió los enfoques de su investigación a diversos ámbitos de la paleobiología. Con el inicio de la universidad democrática en la Transición, Pascual Rivas empezó a participar activamente en la gestión y política académicas, y ocupó diversos cargos en todos los niveles institucionales de la Universidad de Granada y en distintas comisiones de la Junta de Andalucía. Aparte de varios periodos como director del 
Departamento de Estratigrafía y Paleontología, hay que destacar que fue vicerrector de investigación y, posteriormente, rector de la Universidad de Granada a finales de los años 80 y principio de los 90 .

Creemos que una mayoría de científicos que vivieron aquella época en la Universidad de Granada comparten nuestra opinión de que nunca la investigación ha tenido tanto impulso en esta institución como entonces. Con imaginación e iniciativa inusuales hasta el momento en la inercia académica, se establecieron mecanismos de apoyo a la investigación que fueron importados por otras universidades del entorno y aún perduran. De ellos cabe destacar el Plan Propio de Investigación, que ha facilitado el arranque de una carrera académica a muchos investigadores que, por la escasez de otros recursos, tendrían que haber renunciado a realizar su doctorado o estancias postdoctorales. Paralelamente, y desde su posición en la Universidad de Granada, pero actuando en todas las instancias regionales y nacionales, Pascual Rivas fue artífice, con muchos otros, por supuesto, del despegue institucional de la paleontología española en las dos últimas décadas del siglo XX. El impresionante crecimiento del número de plazas de paleontología en las universidades y el incremento en los fondos para investigación en Andalucía, y España en general, no son ajenos a su actividad. Pascual Rivas fue socio fundador de la Sociedad Española de Paleontología y, posteriormente, fue su presidente, probablemente el que ostenta el mandato de mayor duración, y siempre ha sido un socio activo.

Pascual ha sido, y es, lo que hoy se llama un líder de opinión en los distintos niveles en los que ha desarrollado su vida profesional. Ha influido en la manera de ver y de abordar los problemas desde nuestro departamento a toda la Universidad de Granada; y desde ésta a los departamentos de cultura, universidades e investigación que, con distintos nombres, han regido la enseñanza superior y la investigación, no solo paleontológica, en Andalucía. Sus opiniones se han abierto durante muchos años a un espectro social mucho más amplio, gracias a sus continuas colaboraciones en la prensa local de Granada y a su participación semanal en tertulias radiofónicas de cadenas regionales y nacionales. De Pascual se puede decir lo que decía Tristram Shandy de su padre: "whose way was to force every event in nature into an hypothesis". Sus hipótesis siempre suelen ser originales y, por razones que se escapan a los que no lo conocen bien, casi siempre relacionadas de una manera u otra, antes o después, con las vacas lebaniegas. Con ello ha sido muy estimulante y divertido trabajar con él, compartir muchos días de campo y laboratorio y, sobre todo, muchas horas de charla sobre cualquier asunto del universo.

Los contenidos del presente volumen de algún modo reflejan la trayectoria profesional de Pascual Rivas, no porque correspondan a temas paleontológicos que él haya trabajado, como ocurre en varios casos, sino porque han sido realizados por un amplio grupo de paleontólogos que creen que merece un reconocimiento al final su carrera. Es un "libro de amigos" que homenajea a un profesor de universidad que dedicó muchos esfuerzos al desarrollo de la paleontología española, y mucha cordialidad para promover las buenas relaciones entre los miembros de nuestra comunidad científica. Aquí se han reunido trabajos de morfología, taxonomía, tafonomía, paleoecología, paleobiogeografía, estratigrafía de alta resolución, desarrollo socio-económico, e historia conceptual de la paleontología. Se tratan grupos de fósiles muy distintos, de edades que van del Cámbrico al Cuaternario. Estos artículos pueden verse como una representación de la diversidad de temas y enfoques que ha alcanzado en España nuestra ciencia, diversidad que en buena medida se debe a la labor científica e institucional de Pascual y otros paleontólogos de su generación.

Co-editores invitados

Juan C. BRAGA

Julio AGUIRRE

Francisco J. RODRÍGUEZ-TOVAR

Dpto. Estratigrafía y Paleontología, Universidad de Granada 